\title{
Cognitive impairment in Wilson's disease
}

\author{
Norberto Anizio Ferreira Frota ${ }^{1}$, Paulo Caramelli ${ }^{2}$ Egberto Reis Barbosa ${ }^{3}$
}

\begin{abstract}
Wilson's disease (WD) or hepatolenticular degeneration is a rare, genetic and systemic disease, caused by a deficit in the metabolism of copper, leading to its accumulation in different organs, mainly the liver, followed by the central nervous system, especially the basal ganglia. When symptoms begin between the second and third decades of life, approximately $50 \%$ of the patients show neurological symptoms. Although dystonia and dysarthria are the most common neurological signs, cognitive changes have been reported since the first cases were described in 1912. Memory change is one of the most common impairments, but other cognitive changes have been reported, including dementia in untreated cases. In this article we review the cognitive changes in WD patients and the occurrence of dementia.
\end{abstract}

Key words: Wilson's disease, cognition, dementia.

\begin{abstract}
Comprometimento cognitivos na doença de Wilson
Resumo - Doença de Wilson (DW) ou degeneração hepatolenticular é uma doença sistêmica genética rara, causada por um déficit no metabolismo do cobre, levando a sua acumulação in diferentes órgãos, principalmente o fígado, seguido pelo sistema nervoso central, especialmente os gânglios da base. Quando os sintomas iniciam entre a segunda e terceira décadas de vida, aproximadamente $50 \%$ dos pacientes apresentam sintomas neurológicos. Apesar de distonia e disartria serem as alterações neurológicas mais comuns, mudanças cognitivas tem sido relatadas desde os primeiros casos em 1912. Alteração de memória é o comprometimento mais comum, mas outras alterações foram descritas, incluindo demência em casos não tratados. Nesse artigo nós revisaremos as alterações cognitivas em pacientes com DW e a ocorrência de demência.

Palavras-chave: Doença de Wilson, cognição e demência.
\end{abstract}

Wilson's disease (WD) or hepatolenticular degeneration is a rare genetic and multisystemic condition which affects mainly the liver, followed by the central nervous system (CNS), cornea and kidneys. Its incidence is $1-2$ cases per 100,000 persons, with prevalence of 1:30,000 (homozygotes) and 1:100 to 1:2,000 (heterozygotes). ${ }^{1}$

The first description of a patient with this condition was reported by Friedrich Theodor von Frerichs in $1861 .^{2}$ However, it was only after Alexander Kinnier Wilson described a series of cases in 1912 that the condition became well known. At the time, four young members of the same family were studied; the clinical features involved involuntary movement, spasticity, dysarthria, dysphagia and psychiatric symptoms with a fatal evolution which consisted, from a pathological perspective, of cirrhosis and softening of the lenticular nucleus. ${ }^{3}$ In the following year Rumpel linked this condition to copper. ${ }^{4}$ The locus of WD is now known to lie in the long arm of chromosome 13, responsible for encoding ATP7B expressed predominantly in the liver. ATP7B is responsible for transporting copper within cells so that it can be subsequently incorporated into ceruloplasmin and excreted through the bile. This is the main excretion pathway for copper. Thus, defects in this enzyme cause the copper to accumulate inside the hepatocyte cytoplasm and lead to later necrosis and release into the blood plasma. Subsequently, this metal accumulates elsewhere, such as in the basal ganglia and cornea. ${ }^{5-8}$ Over 250 types of mutations have been found to date, making clinical features heterogeneous. In Brazil, the most common mutations are found in loci 3402DelC and L708P. ${ }^{9}$

Where symptoms of WD appear in childhood, hepatic features are the most commonly occurring. When symptoms manifest between the second and third decades of life, approximately $50 \%$ of the patients show neurologi-

${ }^{1} \mathrm{MD}$, General Hospital of Fortaleza and Department of Neurology, University of São Paulo School Medicine, São Paulo, SP, Brazil. ${ }^{2} \mathrm{MD}, \mathrm{PhD}, \mathrm{Behavioral}$ and Cognitive Neurology Unit Faculty of Medicine, Federal University of Minas Gerais, Belo Horizonte, MG, Brazil. ${ }^{3} \mathrm{MD}$, PhD, Department of Neurology, University of São Paulo School Medicine, São Paulo, SP, Brazil.

Norberto Anizio Ferreira Frota - Rua República do Líbano, 992 / Ap 801 - 60160140 Fortaleza CE - Brazil. E-mail: naffrota@yahoo.com.br

Disclosure: The authors reports no conflicts of interest.

Received November 19, 2008. Accepted in final form February 20, 2009. 
cal symptoms. The most common of these, according to a study of a Brazilian sample, are: dysarthria (91\%), abnormal gait (75\%), risus sardonicus (72\%), dystonia (69\%), rigidity (66\%), bradykinesia (58\%), rest tremor (55\%), dysphagia (50\%), postural instability (49\%), cerebellar alterations $(28 \%)$, chorea (16\%) and athetosis $(14 \%) .{ }^{10}$

There are several structures or regions in the CNS which can be affected, including the cerebellum, thalamus and subcortical white matter, although the basal ganglia is predominantly affected. ${ }^{11}$

The medical treatment of Wilson disease's patients can be based on the use of chelating agents. These are capable of raising blood copper concentration and its renal excretion and this could explain why some patients may experience worsening of symptoms in the beginning of treatment. This initial toxicity is the reason why some authors prefer the use of zinc sulphate or acetate, which has a less aggressive profile in terms of collateral symptoms and is a copper lowering agent from the outset. Zinc treatment has been indicated ideally for medical treatment naïve individuals. ${ }^{12}$

Cognitive abnormalities, although acknowledged since the first description by Wilson, are under discussion to this day. Cummings cited the study conducted by Wilson as the first description of a case of subcortical dementia, a dementia pattern consisting of executive dysfunction, apathy and depression, as opposed to cortical dementias, in which aphasia, agnosia, apraxia and amnesia are predominant, such as in Alzheimer's disease. ${ }^{13}$ This kind of dementia has been associated to serum free copper. Patients with Alzheimer's disease and a high level of blood free copper have a worse outcome than patients with normal levels. ${ }^{14}$

Several studies have since tried to evaluate the cognitive abnormalities of WD, classifying it as a cause of reversible subcortical dementia. However, results are conflicting.

In this paper we discuss the cognitive abnormalities shown by patients suffering from WD and investigated whether they lead to functional impairment.

\section{Cognitive abnormalities}

Cognitive deterioration in patients suffering from WD has been described since the first cases were reported in the early $20^{\text {th }}$ century. ${ }^{3}$ Patients showing neurological motor symptoms usually also present with, from the outset, changes in behavior or cognitive decline. ${ }^{15}$ This decline appears in approximately $25 \%$ of the patients. ${ }^{16}$ Depending on the test used and whether the patients present with more hepatic or neurological symptoms, this figure can reach up to $40 \% .^{17}$

Patients displaying exclusively hepatic symptoms tend to perform the same as normal voluntary participants on cognitive tests. ${ }^{18,19}$ Patients displaying neurological symptoms performance worse in comparison with control groups ${ }^{18-21}$ and with asymptomatic patients or those who have exclusively hepatic conditions. Only one study found slightly higher performance in executive functions when comparing patients with neurological manifestations against those with hepatic symptoms. ${ }^{20}$

Patients suffering from WD show a significantly poorer performance on global cognitive tests such as the MiniMental State Examination ${ }^{17}$ and the Mattis Dementia Rating Scale ${ }^{18}$ compared to healthy voluntary participants. ${ }^{17,18}$ Motor features may have influenced this impaired performance. ${ }^{18}$ Intelligence tests such as the WAIS ${ }^{18,19}$ and other similar instruments ${ }^{21}$ have shown conflicting results. One study found poorer performance on the WAIS test, restricted to the non-verbal part ${ }^{18}$ while another found performance to be worse in both verbal and non-verbal components. ${ }^{19}$ Other intelligence tests have revealed no statistical difference in relation to control groups. ${ }^{21}$ Even in those studies which have encountered differences in performance, these lay within the range of normality (low average). ${ }^{18,19}$

Memory deficits have been described by several authors. ${ }^{18,19,22}$ These authors have found that patients suffering from WD show lower capacity to both learn words and recall them across all stages of the Rey Auditory-Verbal Learning Test (RAVLT). They also observed a small difference in learning rate between the first and the second exposure to stimuli in this patient group. ${ }^{19}$ However, no difference was observed in the rate of loss of information between the last exposure and recall after interference, nor any difference in recognition. ${ }^{19,22}$ The results profile in this memory test resembled that of patients suffering from Huntington's disease which differs from the profile found in Alzheimer's dementia. Results are conflicting in non-verbal memory tests such as Benton's, and in computerized tests. Although Seniow ${ }^{19}$ encountered poorer performance in relation to control groups, Lang ${ }^{21}$ and Portala et al. ${ }^{20}$ observed no significant difference. These studies with negative findings pooled all patients with WD into a single group regardless of the clinical features (neurological, hepatic or asymptomatic). This may have contributed to the negative findings.

Tests which evaluate executive functions such as Raven's Progressive Matrices, also show poorer performance by patients with WD compared with healthy controls. Tests which also evaluate reasoning have shown a difference between patients displaying neurological symptoms and control groups. ${ }^{18,20,21}$ No differences have been observed compared with performance of control groups on semantic verbal fluency (animals) ${ }^{18}$ although performance was significantly worst in phonemic fluency. ${ }^{23}$ The study by Lang also observed a difference in phonemic fluency between the two groups, although the author did not consider this 
result to be clinically significant. ${ }^{21}$ Language tests such as the Boston Naming Test have not shown any difference between the two groups. ${ }^{18}$ These findings suggest that the difference in performance between the two types of fluency might be more strongly attributable to dysfunction in frontal-subcortical circuits than to a language problem or dysarthria. Similar findings were found in Friedreich's ataxia. ${ }^{23}$ This difference in fluency has previously been described as a differential between Alzheimer's disease and frontotemporal dementia. ${ }^{24}$

Other tests which evaluate this circuit, such as forward and backward digit span, have shown no differences between WD patients and controls, ${ }^{18,21}$ although it did display abnormal results in another evaluation..$^{19}$ The performance on the Wisconsin Card Sorting Test has also been described not to differ between patients and controls, revealing a similar number of responses and perseverant errors. ${ }^{18}$ Evaluations carried out using computerized tests have shown lower performance in digit span and divided attention tests, with an increase in perseverating responses. ${ }^{21} \mathrm{An}$ increase in response time for both visual and auditory stimuli, as well as in perception speed was evident. ${ }^{20,21}$ In spite of these findings, no greater difficulty in information processing was observed. ${ }^{25}$

The summary of cognitive changes described in WD patients is depicted in Table 1.

\section{Cognitive abnormalities and clinical features/imaging}

Initially, abnormalities in memory and some other cognitive tests were associated with the impact of the motor features on such patients. ${ }^{18}$ However, following evaluation of the motor features by means of scales, no relationship has been observed between the degree of motor impairment and performance on the WAIS. Similarly, no correlation has been found between the psychiatric symptoms and cognitive features. These three domains of impairment seem to act independently. ${ }^{26}$

Patients who have had the disease for a longer period show poorer performance on visuospatial tests while older subjects show impaired performance on executive function tests. Patients who have an earlier onset also present poorer visuospatial performance and take longer to carry out motor activities. ${ }^{20}$ No correlation has been found between the motor or cognitive features and copper levels or ceruloplasmin. ${ }^{17}$

Evaluation of patients displaying both neurological symptoms and cranial computed tomography (CT) scan abnormalities revealed poorer performance on digit arrangement tests than patients showing no CT abnormalities. However, the author did not specify the nature of the abnormalities found. ${ }^{21}$
Patients displaying WD neurological symptoms with lesions confined to the basal ganglia were compared with patients displaying additional lesions in other areas using brain magnetic resonance imaging (MRI) exams. It was evident that patients who had lesions restricted to the basal ganglia also showed lower performance to that of control groups across all tests, although with less statistical significance when evaluated together with the patients who had additional lesions in other areas. Comparing both groups of neurological patients, there was a tendency toward better IQ performance and execution, albeit statistically insignificant, and with regard to comprehension, digit span, object assembly, block design and digit symbol subscores, better performance was seen by patients who had lesions limited to basal ganglia. However there was no difference between Rey's and Benton's memory tests, nor Raven's matrices, which suggests that even if the condition were restricted to the basal ganglia it can also lead to cognitive abnormalities. ${ }^{19}$

Although two studies have already made clear that functional SPECT exams can be more sensitive than MRI for diagnosing abnormalities in patients suffering from $\mathrm{WD},{ }^{27,28}$ such exams can show abnormalities even in patients who have hepatic symptoms only. No study has yet compared these abnormalities with motor clinical features or cognitive abnormalities.

\section{Dementia in Wilson's disease}

The accounts produced by Wilson ${ }^{3}$ in the early $20^{\text {th }}$ century described, together with the motor symptoms of the condition, neuropsychiatric abnormalities which caused functional impairment in these patients. These features led Cummings to refer to WD as an etiology of dementia of the subcortical type. ${ }^{13}$

Several clinical accounts have since described cases of WD which showed cognitive abnormalities leading to functional impairment, corresponding to clinical features that resemble a dementia syndrome. ${ }^{3,29,30}$ All these studies demonstrated motor and cognitive improvement after initiating clinical treatment for WD. This observation led to WD being categorized as a reversible dementia, both after clinical treatment ${ }^{29,30}$ or after hepatic transplant. ${ }^{31}$ Cognitive abnormalities may persist even after treatment, as discussed previously.

Performance by WD patients on the several tests discussed earlier, although inferior to that of control groups, has proven to be mostly within normal levels (on average within 1 standard deviation). ${ }^{18,19,21}$ The fact that components such as language, semantic verbal fluency and performance on the Wisconsin Card Sorting Test were preserved has prevented some authors from considering WD as a dementia syndrome. ${ }^{18}$ Another point raised was that 
Table 1. Tests results in WD.

\begin{tabular}{|c|c|c|c|c|c|}
\hline Cognitive domain & Author & $\mathbf{N}$ & Patient scores & Control scores & $p$ \\
\hline \multicolumn{6}{|l|}{ Global assessment } \\
\hline MMSE & Sinha et al. & 34 & 24 & - & - \\
\hline DRS & Medalia et al. & 19 & 139.26 & 142.2 & 0.014 \\
\hline WAIS - VIQ & Medalia et al. & 19 & 99.0 & 106.87 & 0.153 \\
\hline WAIS - PIQ & Medalia et al. & 19 & 91.79 & 104.93 & 0.008 \\
\hline WAIS - FIQ & Medalia et al. & 19 & 95.53 & 106.4 & 0.047 \\
\hline WAIS - VIQ & Seniow et al. & 50 & 97.9 & 112.76 & $<0.001$ \\
\hline WAIS - PIQ & Seniow et al. & 50 & 98.52 & 115.22 & $<0.001$ \\
\hline WAIS - FIQ & Seniow et al. & 50 & 98.83 & 115.12 & $<0.001$ \\
\hline LPS - reasoning & Lang et al. & 17 & 21.71 & 27.0 & $0.009^{\star}$ \\
\hline \multicolumn{6}{|l|}{ Memory } \\
\hline RAVLT & Glaberman et al. & 19 & & & $<0.001$ \\
\hline RAVLT & Seniow et al. & 50 & & & $<0.0001$ \\
\hline Benton & Seniow et al. & 50 & & & $<0.0001$ \\
\hline Benton & Lang et al. & 17 & 13.18 & 13.18 & 0.438 \\
\hline WMS & Medalia et al. & 19 & 101.21 & 114.20 & $<0.01$ \\
\hline \multicolumn{6}{|l|}{ Executive functions } \\
\hline Wisconsin Card Sorting categories & Medalia et al. & 19 & 5.69 & 6 & 0.632 \\
\hline Wisconsin Card Sorting perseverations & Medalia et al. & 19 & 10.16 & 5.06 & 0.164 \\
\hline Raven & Lang et al. & 17 & 42.06 & 49.94 & $0.014^{*}$ \\
\hline Raven & Seniow et al. & 50 & & & $<0.0001$ \\
\hline Digit Span & Seniow et al. & 50 & 5.43 & 7.0 & $<0.05$ \\
\hline Digit Span & Lang et al. & 17 & 10.65 & 10.53 & 0.413 \\
\hline Verbal Fluency FAS & Glaberman et al. & 19 & & & $<0.01$ \\
\hline Verbal Fluency Letter & Lang et al. & 17 & 32.41 & 40.06 & $0.014^{*}$ \\
\hline Verbal Fluency Animals & Medalia et al. & 19 & 20.06 & 21.94 & 0.24 \\
\hline Trail Making A & Medalia et al. & 19 & 44.2 & 28 & 0.014 \\
\hline Trail Making A - errors & Medalia et al. & 19 & 0.05 & 0.06 & 0.25 \\
\hline Trail Making B & Medalia et al. & 19 & 86.4 & 58.1 & 0.018 \\
\hline Trail Making B - errors & Medalia et al. & 19 & 0.26 & 0.33 & 0.25 \\
\hline \multicolumn{6}{|l|}{ Language } \\
\hline Boston & Medalia et al. & 19 & 79.36 & 80.73 & 0.114 \\
\hline Object naming & Lang et al. & 17 & 15.0 & 14.94 & 0.359 \\
\hline \multicolumn{6}{|l|}{ Visuo spatial } \\
\hline Intelligence Structure - mental figure & Lang et al. & 17 & 10.76 & 10.41 & $0.049^{\star}$ \\
\hline Intelligence Structure - mental rotation & Lang et al. & 17 & 8.59 & 10.35 & $0.028^{*}$ \\
\hline \multicolumn{6}{|l|}{ Perceptual Speed } \\
\hline Perceptual Speed & Lang et al. & 17 & 23.76 & 17.53 & 0.0025 \\
\hline Perceptual Maze Test & Portala et al. & 19 & - & - & $<0.05$ \\
\hline
\end{tabular}

MMSE, Mini Mental State Examination; DRS, Dementia Rating Scale; WAIS, Wechsler Adult Intelligence Scale; VIQ, Verbal IQ; PIQ, Performance IQ; FIQ, Full-scale IQ; LPS, Achievement Assessment System; RAVLT, Ray Auditory Verbal Learning Test; WMS, Wechsler Memory Scale. ${ }^{\star}$ The author used alpha adjustment with $p<0.00263$.

the majority of patients were ambulatory and independent with regard to their daily and routine activities, ${ }^{21}$ although none of the studies evaluated functional performance.

Systematic studies involving a greater number of WD patients have excluded subjects whose neurological state was more severely impaired. This might have contributed to the negative finding of dementia in WD for treated patients. ${ }^{19} \mathrm{~A}$ recent Brazilian study evaluating a large number of cases, including subjects manifesting various levels of neurological impairment, found a prevalence of dementia of $5 \%$ among these patients. ${ }^{10}$

Criteria for dementia diagnosis applied when most of 
the studies were carried out, considered memory impairment and progressive clinical decline to be necessary to reach this diagnosis. Nowadays, it is known that a static pattern for cognitive deficits is sufficient, and that memory impairment involves the learning domain and not only delayed recall. The diagnosis of some types of dementia is now even dismissing the mandatory presence of memory impairment, as is the case for dementia with Lewy bodies, ${ }^{32}$ dementia associated with Parkinson's disease ${ }^{33}$ and frontotemporal lobar degeneration. ${ }^{34}$ Thus, the lack of WD patients diagnosed with dementia even after clinical treatment could be the result of underestimated data. Regardless of this, it is already known that early treatment has an important impact on the course of WD..$^{35}$

\section{Conclusion}

WD is a rare neurological condition associated not only to motor impairment but also to cognitive abnormalities that can be severe in the initial stages if not treated and that remain, albeit in mild form, after commencing treatment. These abnormalities occur mainly with regard to attention, executive functions and memory (encoding), but may also appear even when only the basal ganglia are affected. Early diagnosis and treatment are crucial for better prognosis.

\section{References}

1. Reilly M, Daly L, Hutchinson M. An epidemiological study of Wilson's disease in Ireland. J Neurol Neurosurg Psychiatry 1993;56:298-300.

2. Owen CA. Wilson's Disease. The Etiology, Clinical Aspects, and Treatment of Inherited Copper Toxicosis. New Jersey: Neyes;1981:1-22.

3. Wilson SAK. Progressive lenticular degeneration: a familial nervous disease associated with cirrhosis of the liver. Brain 1912;34:295-507.

4. Rumpel A. Über das Wesen und die Bedeutung. der Leberveränderungen und der Pigmentierungen bei den damit verbunden Fällen von Pseudosklerose, zugleich ein Beitrag zur Lehre von der Pseudosklerose (Westphal-Strümpell). Dtsch Z Nervenkeilk 1913;49:54-73.

5. Bowcock AM, Farrer LA, Cavalli-Sforza LL, et al. Mapping the Wilson's disease loccus to a cluster of linked polymorphic marker on chromosome 13. Am J Hum Genet 1987;41:27-35.

6. Lutsenko S, Barnes NL, Bartee MY, Dmitriev OY. Function and Regulation of Human copper-transporting ATPases. Physiol Rev 2007;87:1011-1046

7. Bull PC, Thomas GR, Rommens JM, Forbes JR, Cox DW. The Wilson disease gene is a putative copper transporting P-type ATPase similar to the Menkes gene. Nat Genet 1993;5:327-337.

8. Petrukhin K, Lutsenko S, Chernov I, Ross BM, Kaplan JH, Gilliam TC. Characterization of the Wilson disease gene encod- ing a P-type copper transporting ATPase: genomic organization, alternative splicing, and structure/function predictions. Hum Mol Genet 1993;3:1647-1656

9. Deguti MM, Genschel J, Cançado ELR, et al. Wilson Disease: Novel Mutations in the ATP7B Gene and Clinical Correlation in Brazilian Patients. Human Mutation 2004;23:398-406.

10. Machado A, Chien HF, Deguti MM, et al. Neurological manifestations in Wilson's disease: Report of 119 cases. Mov Disord 2006;21:2192-2196.

11. Scheinberg IH, Sternlieb I, Walshe JM. Wilson's disease and Kayser-Fleischer rings. Ann Neurol 1986;19:613-614.

12. Hoogenraad TU. Paradigm shift in treatment of Wilson's disease: zinc therapy now treatment of choice. Brain Dev. 2006; 28:141-146

13. Cummings J. Subcortical dementia. Neuropsychology, neuropsychiatry, and pathophysiology. Br J Psychiatry 1986; 149:682-697.

14. Squitti R, Bressi F, Pasqualetti P, et al. Longitudinal prognostic value of serum "free" copper in patients with Alzheimer disease. Neurology 2009;72:50-55.

15. Walshe JM, Yealland M. Wilson's disease: the problem of delayed diagnosis. J Neurol Neurosurg Psychiatry 1992;55: 692-696.

16. Lauterbach EC, Cummings JL, Duffy J, et al. Neuropsychiatric correlates and treatment of lenticulostriatal disease: a review of the literature and overview of research opportunities in Huntington's, Wilson's and Fahr's diseases. J Neuropsychiatry Clin Neurosci 1998;10:249-266.

17. Sinha S, Christopher R, Arunodaya GR, et al. Is low serum tocopherol in Wilson's disease a significant symptom? J Neurol Sci 2005;228:121-123.

18. Medalia A, Isaacs-Glaberman, Scheinberg H. Neuropsychological impairment in Wilson's disease. Arch Neurol 1988;45:502-504.

19. Seniow J, Bak T, Gajda J, et al. Cognitive functioning in neurologically symptomatic and symptomatic forms of Wilson's disease. Mov Disord 2002;17:1077-1083.

20. Portala K, Levander S, Westermark et al. Pattern of neuropsychological deficits in patients with treated Wilson's disease. Eur Arch Psychiatr Clin Neurosci 2001;251:262-268.

21. Lang C. Is Wilson's disease a dementing condition ?. J Clin Exp Neuropsychol 1989;11:569-570.

22. Glaberman KI, Medalia A, Scheinberg IH. Verbal recall and recognition abilities in patients with Wilson's disease. Cortex 1989;25:353-361.

23. De Nobrega E, Nieto A, Barroso J, Montón F. Differential impairment in semantic, phonemic, and action fluency performance in Friedreich's ataxia: Possible evidence of prefrontal dysfunction. J Intern Neuropsychol Soc 2007;13:944-952.

24. Rascovsky K, Salmon DP, Hansen LA, Thai LJ, Galasko D. Disparate letter and semantic category fluency deficits in au- 
topsy-confirmed frontotemporal dementia and Alzheimer's disease. Neuropsychology 2007;21:20-30.

25. Littman E, Medalia A, Senior G, Scheinberg IH. Rate of information processing in patients with Wilson's disease. J Neuropsychiatry Clin Neurosci 1995;7:68-71.

26. Medalia A, Galynker I, Scheinberg H. The interaction of motor, memory, and emotional dysfunction in Wilson's disease. Biol Psychiatry1992;31:823-826.

27. Giagheddu M, TamburiniG, Piga M, et al. Comparison of MRI, EEG, Eps and ECD-SPECT in Wilson's disease. Acta Neurol Scand 2001;103:71-81

28. Piga M, Murru A, Satta L, et al. Brain MRI and SPECT in the diagnosis of early neurological involvement in Wilson's disease. Eur J Med Mol Imaging. 2008;35:716-724.

29. Rosseli M, Lorenzana P, Rosseli A, Vergara I. Wilson's disease, a reversible dementia: case report. J Clin Exp Neuropsychol 1987;9:99-406.
30. Riley D, Wiznitzer M, Schwartz S, Zinn AB. A 13-year-old boy with cognitive impairment, retinoblastoma, and Wilson disease. Neurology 2001;57:141-143.

31. Stracciari A, Tempestini A, Borghi A Guarino M. Effect of Liver Transplantation on Neurological Manifestations in Wilson Disease. Arch Neurol 2000;57:384-386.

32. McKeith IG, Dickson DW, Lowe J, et al. Diagnosis and management of dementia with Lewy bodies: third report of the DLB Consortium. Neurology 2005;65:1863-1872.

33. Emre M, Aarsland D, Brown R, et al. Clinical diagnostic criteria for dementia associated with Parkinson's disease. Mov Disord 2007;22:1689-1707.

34. Neary D, Snowden JS, Gustafson L, et al. Frontotemporal lobar degeneration: a consensus on clinical diagnostic criteria. Neurology 1998;51:1546-1554.

35. Walshe JM, Yealland M. Wilson's disease: the problem of delayed diagnosis. J Neurol Neurosurg Psychiatry 1992; 55:692-696. 